https://doi.org/10.48009/1_iis_2010_347-351

\title{
OUTSOURCING XBRL FINANCIAL STATEMENT FILING: A CASE STUDY OF PRACTICES IN TWO PUBLIC FIRMS
}

\author{
Deb Sledgianowski, Hofstra University, Deb.Sledgianowski@Hofstra.du \\ Robert Fonfeder, Hofstra University, Robert.Fonfeder@Hofstra.edu \\ Jackson Lam, KPMG, JTLam@KPMG.com
}

\begin{abstract}
Publicly-held companies in the U.S. are now being required by the Securities Exchange Commission (SEC) to file their financial reports using the tagging standard of Extensible Business Reporting Language (XBRL). This interactive data requirement requires all U.S. traded firms to comply by 2011. Our case study examines two accelerated filers to gain insight into their decision whether to in-source or outsource implementation of XBRL filing based on

the eight characteristics of the XBRL Client-Vendor Outsourcing Relationship [5]. The eight characteristics are (1) client-vendor relationship, (2) company size, (3) outsourcing contract, (4) intellectual property, (5) communication, (6) custom functionality, (7) task complexity, and (8) vendor's skills.
\end{abstract}

Keywords: eXtensible Business Reporting Language, XML, Outsourcing, Accounting

\section{INTRODUCTION}

XBRL is an open source markup programming language that uses standard tags based on taxonomies developed by the www.xbrl.org consortium. These tags are used to label each individual element of data to enable them to be identified by other software applications. XBRL can be used to electronically communicate business and financial information both intra- and inter-organizationally. A mandate has recently been issued by the SEC requiring all publicly traded U.S. companies to use the XBRL language as an information technology to facilitate the transmission of financial statements that publicly held companies file with the SEC. For example, when electronically filing its $10-\mathrm{K}$ and $10-\mathrm{Q}$ statements using XBRL, a company would code a tag named "us-gaap:Revenues" along with its U.S. Generally Accepted Accounting Principles (GAAP) revenue amount on its income statement. This tag signifies that the data following the tag is the numerical amount of the "TOTAL REVENUE" element from its financial statement.
The SEC's interactive data ruling affects over 10,000 domestic and foreign issuers who prepare their financial statements under U.S. GAAP or IFRS. The SEC estimates that preparation costs to a company submitting its first interactive data financial statements with detailed footnotes and schedules could average $\$ 30,700$ and that the number of hours required to tag face financials could average 125 hours for the first submission and 17 hours for subsequent submissions. In a survey of chief audit executives taken in 2008, a year prior to the SEC mandate, a majority of the respondents indicated that they that they are not at all familiar with XBRL and that more knowledge and guidance should be provided to the profession [5]. There are thousands of public companies yet to file their first financial statements using XBRL. The recent ruling by the SEC mandating that public companies and mutual funds file their financial reports using XBRL necessitates that these companies contemplate how to implement this requirement.

Prior to issuing its mandate, the SEC conducted a voluntary filer program. Over half of the 50 companies participating in the SEC's voluntary program for XBRL filing reported that they outsourced their XBRL activities [3]. Given the propensity for firms to outsource their XBRL filing requirements, we were interested in determining factors that firms should consider in their decision to outsource. Our previous research [9] presents a model suggesting eight characteristics of sourcing decisions firms should consider when developing an XBRL implementation plan and deciding whether the project should be outsourced or done in-house. A brief description of the eight characteristics is as follows:

1. Client-Vendor Relationship: Companies should consider leveraging an existing relationship they may have with a service provider who is also now offering XBRL conversion services. 
2. Company Size: Firms considering outsourcing their XBRL implementation should consider outsourcing to a vendor similar in size. Firms outsourcing IT-related services tend to engage the services of similar sized firms, especially small-tomedium sized firms [7].

3. Outsourcing Contract: Firms should consider using a detailed and comprehensive contract with their outsourcing vendor to formalize their agreement. But having a close and trust-based relationship, as may exist with a service provider who is already providing other services, can act as a proxy to formal contracts and could lower the risks that precipitate the need for outsourcing contracts $[4,6]$.

4. Intellectual Property: Financial statement information isn't considered intellectual property, rather it is part of the public domain, bur firms should consider whether any custom development and programming needs to take place, and if so, who owns the resulting code.

5. Communication: Effective communication skills across internal functional areas and with external vendors are important for the successful implementation of interactive data filing.

6. Custom functionality: If a firm can easily use one of the existing XBRL software mapping packages to solve its business requirements, then it can be a much faster and less expensive solution than developing a solution in-house or outsourcing the implementation. If an organization's business requirements require custom functionality to provide a unique capability, then a solution implemented in-house may be necessary.

7. Task Complexity: One of the main determinants of a sourcing strategy for an IT implementation is the degree of task complexity. Organizations may want to initially outsource XBRL filing and as they become more comfortable with the process, they may want to consider implementing it in-house.

8. Vendor's Skills: Organizations should consider the level of experience a vendor has with XBRL filing and its understanding of the different XBRL standards, since XBRL is a relatively new information technology. One of the most common reasons for outsourcing IT-related tasks is to utilize the service provider's technical skills [1].

Extending our previous research, the primary objective of our current study was to assess the feasibility of using the "Characteristics of XBRL Client-Vendor Outsourcing Relationship" model [9] to determine the degree that these characteristics are being considered by filing firms, so that we can determine whether to use this model as a basis for a more detailed quantitative and cross-sectional study.

\section{METHODOLOGY}

We used a case study approach performing an indepth investigation of two publicly-traded firms, one categorized by the SEC as a large accelerated filer with a public float greater than $\$ 5$ billion and required to submit its quarterly and annual SEC filings in XBRL starting June 2009, and the other firm categorized as an accelerated filer with a public float greater than $\$ 750$ million and less than $\$ 5$ billion and required to submit its quarterly and annual SEC filings in XBRL starting June 2010. Yin [10] suggests using a case study design to answer "how" and "why" questions. Since we are interested in finding out how and why firms implementing XBRL filing are utilizing outsourcing, we used a case study method to help validate our model and determine whether it is applicable to the implementation of mandatory XBRL filing. We conducted detailed interviews with these two accelerated filers. Our interviews were conducted after the first firm's initial XBRL filing and before the second firm's initial XBRL filing.

\section{XBRL SERVICE PROVIDERS}

The US mandate on XBRL reporting has generated tremendous competition among software vendors, as well as document services firms (a.k.a. financial printers). Document services firms such as Merrill Company, Bowne \& Company Inc., IKON Office Solutions Inc., and R.R. Donnelley \& Sons Company provide printing, distribution, and electronic processing of SEC filings and documents related to corporate transactions. These companies are the major players in the full-service XBRL conversion business and many of them have been directly involved as a member of the xbrl.org/us consortium 
since it's foundation and during the voluntary filing program.

According to Merrill Corporation's website, its "XBRL team has practical experience working with taxonomies; implementation, documentation" and they offer to "provide a complete end-to-end XBRL solution with services ranging from expert consulting, mapping, tagging and validating to compliant filing with the SEC - managed and controlled in-house by Merrill's own XBRL team of experts."

Many companies deciding how to comply with the SEC mandate over the next few years will choose to implement XBRL internally with the use of "bolt-on" software - a solution that involves installing add-on software that enables drag-and-drop mapping of the financial statement elements in a traditional electronic format, such as a spreadsheet, to the tagged items from a list of standard tags from the appropriate XBRL taxonomy. It is important to mention that several software vendors already had "primitive" XBRL application offering as XBRL was considered "the next big thing" for almost a decade prior. But software firms did not seriously commit time and resources to the latest XBRL applications until the SEC mandate was imminent. Now that the XBRL mandate has been finalized, software vendors such as Fujitsu, Hitachi, Altova, and Rivet Software offer user-friendly software that companies can use inhouse to tag financial reports in XBRL format.

One such application is Rivet Software's Dragon Tag XBRL Enabler bolt-on product that integrates with Microsoft Office as an add-in application. Dragon Tag enables the creation of interactive data filings from financial statements (and accompanying notes) in Microsoft Word and Excel documents." Dragon Tag offers features such as "drag-and-drop" XBRL tagging in Excel and Word, review and validation features for checking correctness/completeness and a taxonomy extension "wizard" for custom extensions if necessary.

Also, well-known software vendor SAP recently launched "XBRL Publisher" in partnership with XBRL software provider UBMatrix. This application permits users of SAP applications to tag financial reporting data "aligned with taxonomies for US GAAP" [8]. Some firms such as Clarity Systems, a Canadian based software vendor, even sell a financial reporting system with XBRL reporting capabilities built in. Clarity FSR by Clarity Systems allows for automated tagging of financial statement items by pulling the financial statement values from the source data files.

\section{CASE STUDY}

One firm in our case study is a leading media, telecommunications, and entertainment company that is classified in the services sector. This firm's annual revenue in 2009 was in excess of $\$ 7.4$ billion and it has a market capitalization of almost $\$ 6.2$ billion. The second firm in our case study is in the healthcare sector with its primary business in health plans. This company generated over $\$ 4.6$ billion in revenues in 2009 and has a market capitalization of $\$ 1.36$ billion.

\section{Case 1: Media, Telecommunications, and Entertainment Company Interview}

The Case 1 firm developed a plan to implement XBRL approximately 6-8 months prior to its mandatory filing date. The firm hired an outside vendor to undertake its XBRL plan. According to the Senior VP in charge of Corporate Reporting, the firm had not even considered implementing XBRL inhouse as the firm neither had the requisite knowledge nor the time to obtain the skill-set, any knowledge they did have with XBRL was either self-taught or learned through viewing webinars and reading periodicals.

Although the Case 1 firm realized that the process would not be lengthy, they felt it would not be advantageous to establish a project team just to address their XBRL conversion when the costs to outsource were well within their budget. The firm did not "shop around" for XBRL vendors, but rather used its financial printer, with whom a 20-year relationship had been established. They were comfortable and confident that Merrill, its financial printer, would be able to quickly and seamlessly convert its financial statements into XBRL format. They cited the fact that Merrill was very familiar with its financial statements; this familiarity allowed Merrill's employees to easily participate with the tagging of the financial statement elements. Just as importantly, they felt the pre-established relationship would ensure excellent service. It is interesting to mention that Merrill and this firm do not work under a formal contract, rather they have a verbal agreement.

This large accelerated filer presented its first XBRL statements to the SEC in June 2009 and recognized some issues during the process. They noticed that many of the standard XBRL tags were either not 
appropriate for its line items or were not tailored to its specific industry. And in many cases, the tags provided just didn't fit. To illustrate this issue, this particular firm lumps many accrued liabilities into one line item titled "Other accrued expenses," while an industry competitor uses "Accounts payable and accrued expenses related to trade creditors."

The Case 1 firm feared that picking the closest standard tag would not fully capture the elements of each firm's line item and thus would be misleading and impair comparability. It was also noticed that this firm uses under the "Accrued liabilities classification," a line item titled "Employee related costs." A major competitor in its industry uses "Accrued salaries and wages," which may or may not capture the same elements. If no standard tag exists to depict these items, each firm must employ an extensible (customized) tag. The use of extensible tags, especially by firms in the same industry, would certainly not do much to increase the comparability and informational value of financial statements. Users of their financial data would still be required to study the financial statements or have previous knowledge of the firm to fully utilize the information contained in the financial statements for investment and comparison purposes. Research of early voluntary filers shows there is a good match between the standard tag set and filers' reporting requirements, but significant differences exist across industries [3]

The standard tags do not address the unique nature of each specific business and as a result, $15-20 \%$ of our interviewee's XBRL documents contained customized tags. The firm did point out that as tags are refined, they do expect the use of custom tags to decrease. Although the SEC will continually refine tags and introduce new tags, this particular firm likens these endeavors to hitting a "moving target" as new tags will, most likely, lag behind changing reporting requirements. They pointed out that their primary reason for implementing XBRL was to comply with a government mandate. Finally, they feel it is too early to comment on whether the benefits of XBRL will bring increased comparability and informational value to investors. They do, however, feel that the benefits of XBRL will not be recognized by them.

\section{Case 2: Healthcare Company Interview}

The second firm we interviewed had devised its implementation plan over the year prior to its required compliance date. They also outsourced their
XBRL implementation as it was a low priority project because of its lack of perceived value to the firm. Unlike the Case 1 firm, the Case 2 firm was very conscious of price and did compare other vendors, but in the end selected their financial printer as well to undertake their XBRL plan. As the Senior VP of Information Technology pointed out, they intended to choose their financial printer all along but introduced alternatives to bring down their financial printer's price for the project.

They also cited an on-going relationship with their printer and were confident the printer had the requisite resources to carry out the plan. In contrast to the last firm, the healthcare company requires contracts of their business partners for issues of confidentiality. Similar to the media firm, this firm recognized the importance of working with a company that was familiar with their specific business. Their IT department had considered purchasing an XBRL software package such as Rivet Software's Dragon Tag that would be an "add-in" to its organizational systems, but feared it would confront barriers to acceptance since everything is run on XML. Moreover, they felt that in-house implementation would add "a level of complexity that is not worth the effort" since so many business partners do not use XBRL; they explained that HIPPA transactions run on very strict guidelines and HIPPA does not use XBRL.

The Senior VP of Information Technology admitted to not being trained nor being familiar with XBRL, although he has read trade journals on XBRL and documentation provided by their vendor. The firm's primary reason for XBRL implementation was to be SEC-compliant, followed by global pressure to do so. They, too, are concerned with tags and extensions that do not specifically address their particular firm or their industry. Upon further investigation, we found that there are no tags or extensions, at the moment, that appropriately capture the fact that healthcare companies submit financials with estimated elements such as "Claims payable." Research shows there is a good match between the standard tag set and filers' reporting requirements, but significant differences exist across industries [2].

In addition, the healthcare sector is exposed to significant fraud and over-billing by healthcare providers and third-party billing companies. It would be useful to have a tag that particularly addresses these medical losses incurred, instead of lumping them into one general line item. At this point in time, this particular firm feels that the cost to implement 
XBRL far outweighs the benefits for their organization.

\section{CONCLUSION}

Based on our case study research, the two firms we studied outsourced their XBRL implementation mainly to comply with a newly mandated reporting requirement and saw little perceived organizational value in their XBRL implementation at this time, but feel that XBRL filing is a "work in process". At least for now, the two US firms interviewed, while hardly representative of all US firms, feel that the costs to implement outweigh the benefits to their respective organizations.

We examined the two firms through the lens of the "Characteristics of XBRL Client-Vendor Outsourcing Relationship" model, seeking to find out the "how" and the "why" [10], by determining to what extent the eight characteristics were considered by the two firms in their decisions to outsource. We found that there is some merit to the model that should be further examined using a larger sample.

As more firms are required to comply with the SEC's mandate, a better assessment can be made of whether firms consider these characteristics important in their decision making.

\section{REFERENCES}

1. Aubert, B. A., Rivard S., and Patry, M. (2004), A transaction cost model of IT outsourcing, Information \& Management, Vol. 41, No. 7, pp. 921-932.

2. Choi, V \& Grant, H \& Luzi, A. (2008). Insights from the SEC's XBRL Voluntary Filing Program. The CPA Journal, December, 69-71
3. Bovee, M., Ettredge, L., Srivastava, R. Vasarhelyi, M. (2002). Does the Year 2000 XBRL taxonomy accommodate current business financial-reporting practice?, Journal of Information Systems, 16(2), pp. 165-182.

4. Chou, T., Chen, J., and Pan, S. (2006), The impacts of social capital on information technology outsourcing decisions: a case study of a Taiwanese high-tech firm, International Journal of Information Management, Vol. 26, No. 3, pp 249-256.

5. Institute of Internal Auditors, (2008).Interactive data - eXtensible Business Report Language survey.

6. Koh, C., Ang, S. and Straub, D. W. (2004), IT outsourcing success: a psychological contract perspective, Information Systems Research, Vol.15, No. 4, pp. 356-373

7. Paul, A. (2007), Size impedes SMEs' tryst with outsourcing, The Economic Times, Jan 16, available at: http://www.offshoringtimes.com/Pages/2007/off shore news1456.html (accessed on June 1, 2010).

8. Plourd, K. (2009). SAP plays the data tagging game. CFO.Com, February, pp. 1-3.

9. Sledgianowski, D., Fonfeder, R. \& Slavin, N. (2010). Implementing XBRL reporting. The CPA Journal, August.

10. Yin, R. K. (2003). Case study research: Design and methods (3rd ed.). Thousand Oaks: CA: Sage. 